\title{
Assessment of muscle fatigue after an ultra- endurance triathlon using tensiomyography (TMG)
}

Juan Manuel García-manso , David Rodríguez-Ruiz , Dario RodríguezMatoso, Yves de Saa , Samuel Sarmiento \& Miriam Quiroga

To cite this article: Juan Manuel García-manso , David Rodríguez-Ruiz , Dario RodríguezMatoso , Yves de Saa, Samuel Sarmiento \& Miriam Quiroga (2011) Assessment of muscle fatigue after an ultra-endurance triathlon using tensiomyography (TMG), Journal of Sports Sciences, 29:6, 619-625, DOI: 10.1080/02640414.2010.548822

To link to this article: https://doi.org/10.1080/02640414.2010.548822

册 Published online: 02 Mar 2011.

Submit your article to this journal $₫$

Џll Article views: 795

Citing articles: 44 View citing articles 


\title{
Assessment of muscle fatigue after an ultra-endurance triathlon using tensiomyography (TMG)
}

\author{
JUAN MANUEL GARCÍA-MANSO, DAVID RODRÍGUEZ-RUIZ, \\ DARIO RODRÍGUEZ-MATOSO, YVES DE SAA, SAMUEL SARMIENTO, \& \\ MIRIAM QUIROGA
}

Department of Physical Education, Universidad de Las Palmas de Gran Canaria, Las Palmas, Gran Canaria, Spain

(Accepted 14 December 2010)

\begin{abstract}
In this study, we used tensiomyography (TMG) to assess muscle status immediately after an ultra-endurance triathlon. Maximal radial displacement or deformation of the muscle belly, contraction time, delay time, sustain time, and relaxation time were measured for both legs, and dependent $t$-tests were used to compare means between the beginning and end of the race. The 19 men assessed (age $37.9 \pm 7.1$ years; height $177.5 \pm 4.6 \mathrm{~cm}$; weight: $73.6 \pm 6.5 \mathrm{~kg}$ ) participated in the 2009 edition of the Lanzarote Ironman. Deterioration in the neural response was observed for contraction time $(P=0.008)$ and relaxation time $(P=0.011)$, with a moderate decrease in the response time (sustain time) and a loss in muscle stiffness (deformation of the muscle belly). The effect of muscle fatigue on the rectus femoris and biceps femoris was different. Barely any changes in contraction time, relaxation time, sustain time, and deformation of the muscle belly were observed, while only the contraction response time decreased to a significant extent (reduction in delay time; $P=0.003$ ). The considerable loss in contractile capacity induced by a long-distance race was reflected in changes in the neuromuscular response and fluctuations in the contractile capacity of the muscle. These modifications, derived from a prolonged, exhausting effort, can be assessed in a simple, non-aggressive, non-invasive way using tensiomyography.
\end{abstract}

Keywords: Tensiomyography, Ironman, long-distance race, neuromuscular fatigue, mechanical characteristics of muscle

\section{Introduction}

Fatigue is defined as any decline in muscle performance associated with muscle activity (Allen, Lamb, \& Westerblad, 2008; Fitts, 1994). In sport, the causes of muscle fatigue are complex and not completely understood. They vary in type and degree depending on the characteristics of the exercise that brings on the fatigue. Many factors related to the central nervous system and/or peripheral factors within the skeletal muscles lead to muscle fatigue (Allen \& Westerblad, 2001; Fitts, 2006; Gandevia, 2001; Gibson \& Edwards, 1985; Westerblad, Allen, Bruton, Andrade, \& Lännergren, 1998).

In long-distance sports (e.g. marathon, cycling, ultra-endurance triathlon), the repeated, prolonged use of muscle structures produces changes in the muscle fibre that affect its mechanical capacities and performance capabilities (Hakkinen \& Komi, 1983; Millet et al., 2000, 2002; Nicol, Komi, \& Marconnet, 1991; Viitasalo, Komi, Jacobs, \& Karlsson,
1982). These modifications are reflected in a reduction in force output (Bigland-Ritchie, Furbush, \& Woods, 1986; Cooke, Franks, Luciani, \& Pate, 1998; Coupland, Puchert, \& Ranatunga, 2001; Debold, Dave, \& Fitts, 2004; Nosek, Fender, \& Godt, 1987; Sargeant, Hoinville, \& Young, 1981), a decrease in shortening velocity of the muscle fibres, especially fast-twitch fibres (Bigland-Ritchie et al., 1986; Colliander, Dudley, \& Tesch, 1988; Karatzaferi, Franks-Skiba, \& Cooke, 2008; Linssen et al., 1991), and a slowing down of relaxation time (Edman \& Mattiazzi, 1981; Metzger \& Moss, 1987; Thompson, Balog, Riley, \& Fitts, 1992).

For sports entailing several hours of exercise during which many stretch-shortening cycles occur, the greatest modification of the muscle is generated during the eccentric stage of the muscular contraction, leading to considerable deleterious effects on muscular function (Clarkson, Nosaka, \& Braun, 1992; Davies \& Thompson, 1986; Howell, Chleboun, \& Conatser, 1993; Newham, Jones, \& 
Clarkson, 1987; Prasartwuth, Taylor, \& Gandevia, 2005; Radin, 1986; Sayers et al., 2003). In this case, the muscles affected most will be the extensor muscles of the knee joint (in the landing and takeoff stages) and/or their antagonist muscles (traction in rear foot and leg recovery).

In most studies, muscular fatigue has been assessed by monitoring static or dynamic force, measuring substrates, metabolites or other chemical substances using biochemical techniques, such as lactate, creatine phosphokinase, and hormones, or with electromyography (EMG). This often entails examining muscles using techniques that are either invasive or require the athletes to exercise at times when they are very tired and not in an appropriate state for assessment. We were unable to find any studies that have assessed muscular fatigue after exercise of long duration using the non-invasive technique of tensiomyography (TMG). Krizaj and colleagues (Krizaj, Simunic, \& Zagar, 2008) and Rusu et al. (2009) present protocols that differ considerably based on the origin of the fatigue and lasting less time than a long endurance resistance race. For this reason, we decided to examine the effects of localized muscle fatigue (rectus and biceps femoris) after an ultra-endurance triathlon using this methodology. The ultra-endurance triathlon is a long endurance sport consisting of a $3.8-\mathrm{km}$ swim and a $180-\mathrm{km}$ cycle, followed by a $42.2-\mathrm{km}$ marathon run.

\section{Methods}

\section{Experimental approach to the problem}

This study used tensiomyography (TMG) to examine the possible relationship between a long- distance race and neuromuscular fatigue. We also endeavoured to evaluate the way in which the ultraendurance triathlon affects the mechanical characteristics of the muscle. Thus, maximal radial displacement or deformation of the muscle belly, contraction time, delay time, sustain time, and relaxation time of both legs were measured, and dependent $t$-tests were used for comparisons of means between the beginning and end of the race.

\section{Participants}

Nineteen male participants (age $37.9 \pm 7.1$ years; height $177.5 \pm 4.6 \mathrm{~cm}$; weight $73.6 \pm 6.5 \mathrm{~kg}$ ) with a mean of 12 years of experience in the ultraendurance event were assessed. The performance best times in the 2009 edition of the Lanzarote Ironman (time: $747.1 \pm 105.4$; range: $576.5-$ $959.2 \mathrm{~min}$ ) are shown in Table I for our participants. Table II provides information on the participants' previous month's (mesocycle) average training (Table II).

All participants were fully informed of the potential risks associated with the study and signed written informed consent forms previously approved by the Research Ethics Committee of the ULPGC in line with the criteria of the Helsinki Declaration for research involving human beings.

\section{Tensiomyography}

Radial displacement was measured on the rectus femoris and biceps femoris muscles of both legs using tensiomyography the day before the event and immediately after each participant had crossed the finishing line at the end of the ultra-endurance

Table I. The participants' mean times for the swimming, cycling, and running legs of the 2009 edition of the Lanzarote Ironman.

\begin{tabular}{|c|c|c|c|c|c|c|}
\hline & \multirow[b]{2}{*}{ Final time } & \multicolumn{3}{|c|}{ Legs } & \multicolumn{2}{|c|}{ Transitions } \\
\hline & & Swimming & Cycling & Running & Swimming-cycling & Cycling-running \\
\hline Mean & 12 h $27^{\prime} 02^{\prime \prime}$ & $1 \mathrm{~h} 11^{\prime} 57^{\prime \prime}$ & 6 h $35^{\prime} 56^{\prime \prime}$ & 4 h $23^{\prime} 14^{\prime \prime}$ & $0 \mathrm{~h} 08^{\prime} 34^{\prime \prime}$ & $0 \mathrm{~h} 08^{\prime} 01^{\prime \prime}$ \\
\hline Maximum & 15 h $59^{\prime} 24^{\prime \prime}$ & $1 \mathrm{~h} 35^{\prime} 45^{\prime \prime}$ & 7 h $57^{\prime} 27^{\prime \prime}$ & $6 \mathrm{~h} 18^{\prime} 40^{\prime \prime}$ & 0 h $10^{\prime} 48^{\prime \prime}$ & 0 h $09^{\prime} 38^{\prime \prime}$ \\
\hline Minimum & 9 h $36^{\prime} 46^{\prime \prime}$ & 0 h $57^{\prime} 47^{\prime \prime}$ & 5 h $19^{\prime} 03^{\prime \prime}$ & $3 \mathrm{~h} 00^{\prime} 21^{\prime \prime}$ & 0 h $04^{\prime} 00^{\prime \prime}$ & $0 \mathrm{~h} 03^{\prime} 11^{\prime \prime}$ \\
\hline
\end{tabular}

Table II. The previous month's (mesocycle) average training for the participants.

\begin{tabular}{|c|c|c|c|c|c|c|}
\hline & \multicolumn{2}{|c|}{ Swimming } & \multicolumn{2}{|c|}{ Cycling } & \multicolumn{2}{|c|}{ Running } \\
\hline & Distance & Time & Distance & Time & Distance & Time \\
\hline Week 1 & $2.0 \mathrm{~km}$ & $0 \mathrm{~h} 40^{\prime}$ & $254 \mathrm{~km}$ & $12 \mathrm{~h} 10^{\prime}$ & $22 \mathrm{~km}$ & $2 \mathrm{~h} 10$ \\
\hline Week 2 & $7.6 \mathrm{~km}$ & $2 \mathrm{~h} 22^{\prime}$ & $340 \mathrm{~km}$ & $14 \mathrm{~h} 15^{\prime}$ & $30 \mathrm{~km}$ & $2 \mathrm{~h} 45$ \\
\hline Week 3 & $10.2 \mathrm{~km}$ & 3 h $3^{\prime}$ & $360 \mathrm{~km}$ & $14 \mathrm{~h} 45^{\prime}$ & $62 \mathrm{~km}$ & $5 \mathrm{~h} 40$ \\
\hline Week 4 & $4.0 \mathrm{~km}$ & $1 \mathrm{~h} 20^{\prime}$ & $220 \mathrm{~km}$ & 8 h $20^{\prime}$ & $14 \mathrm{~km}$ & $1 \mathrm{~h} 20^{\prime}$ \\
\hline
\end{tabular}


triathlon. Post-race assessments were conducted within $15 \mathrm{~min}$ of finishing the race. Assessments lasted no more than $10 \mathrm{~min}$. The test consisted of the assessment of the rectus femoris and biceps femoris of both legs.

This technique is a non-invasive means of muscular assessment in which no physical effort is required of the individual being evaluated. A pressure sensor recorded the geometric changes (radial displacement) that occured in the muscle belly when a contraction was produced in response to an external electrical stimulus (Dahmane, Knez, Valencic, \& Erzen, 2000; Valencic \& Knez, 1997; Valencic et al., 2000; Valencic, Knez, \& Simunic, 2001). The sensor used in this investigation was a high-precision digital displacement transducer that was placed perpendicular to the muscle belly with a controlled pre-tension of the sensor tip to the muscle. It provided information as to the mechanical characteristics and the contractile capacity of the superficial muscles measured, including maximal radial displacement or deformation of the muscle belly, contraction time, delay time, sustain time, and relaxation time (Figure 1).

Maximal radial displacement or deformation (Dm) was given by the radial movement of the muscle belly expressed in millimetres. It represented and evaluated muscle stiffness, and varies between individuals depending on their morphological characteristics and the way in which these structures have been trained. Low values, compared with the average, demonstrate high muscle mass and stiffness, whereas high values show a lack of muscle mass or significant muscle fatigue (Dahmane, Valencic, Knez, \& Erzen, 2001; Krizaj et al., 2008; Valencic et al., 2001). Delay time (Td), also known as reaction time or activation time, represented the time it took to reach $10 \%$ of total movement after stimulation. However, it depended on the predominant type of fibre in that skeletal muscle structure, its degree of fatigue, and activation level (Dahmane, Djordjevic, Simunic, \& Valencic, 2005). Contraction time (Tc) was obtained by recording the time from the end of the reaction time $(10 \%$ deformation of the muscle belly) up to $90 \%$ of the maximum deformation. Sustain time (Ts), which is also known as the contraction duration, was the theoretical duration of the contraction. It was calculated by determining the time between the instant when the deformation reached $50 \%$ of its maximum value until the deformation, during relaxation, returned to $50 \%$ of maximum deformation. Relaxation time ( $\mathrm{Tr}$ )

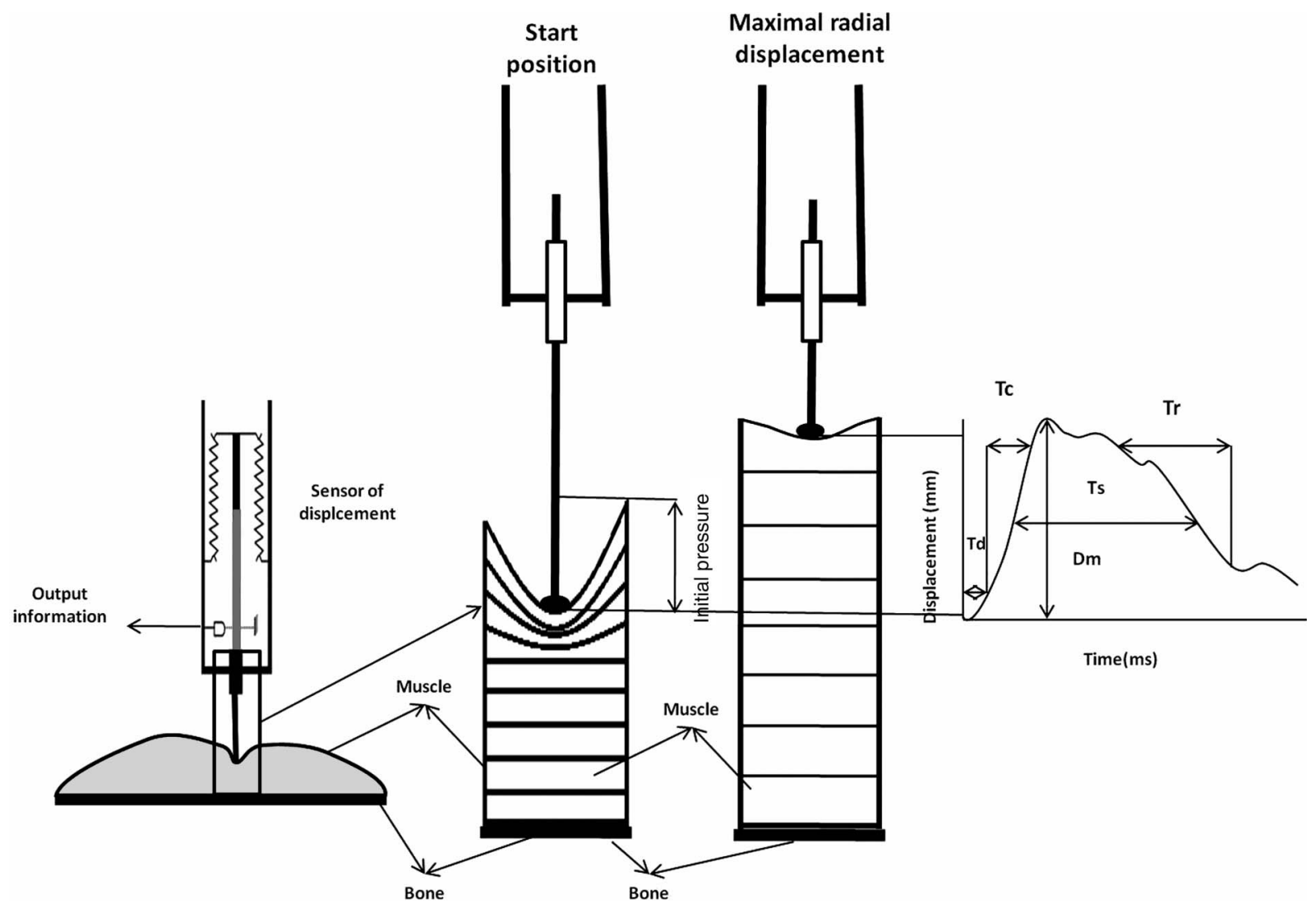

Figure 1. The muscular response to an electrical stimulus obtained by tensiomyography. Maximal radial deformation or displacement of the muscle belly $(\mathrm{Dm})$, contraction time $(\mathrm{Tc})$, delay time $(\mathrm{Td})$, sustain time $(\mathrm{Ts})$, and relaxation time $(\mathrm{Tr})$. 
provided information about level of fatigue, with a high value, compared with normal levels for the participant under assessment, indicating the presence of fatigue.

The extent to which this method may be reproduced and is considered valid was assessed by Krizaj et al. (2008) and Rodríguez-Matoso et al. (2009) following the measurement protocol proposed by the manufacturers.

\section{Statistical analyses}

After verifying the data distribution using a Kolmogorov-Smirnov test, we applied a test for related averages (Student's $t$-test) to compare the results of tensiomyography before and after the race. Statistical significance was set at $P<0.05$. All analyses were performed using SPSS v.14 (SPSS Inc., Chicago, IL).

\section{Results}

The electrical stimulation needed to produce the maximum muscle response was not the same for each participant. In the pre-test and in the post-test, we followed the same protocol of progressively increasing the frequency of the electrical stimulus $(40,70,90$, and $110 \mathrm{~Hz}$ ), and registering the best response of each participant. Muscle fatigue, dehydration, changes in skin temperature, and alteration in skin conductivity constitute some of the factors that may justify this behaviour.

Summed left and right leg mean values and standard deviations for delay time, contraction time, relaxation time, sustain time, and maximal radial displacement or deformation of the biceps femoris before and after the ultra-endurance triathlon are presented in Table III. Muscle fatigue and potentiation are important physiological processes, and are investigated by practically all methods used to study muscle contraction properties. In our study, an overall deterioration in the neural response (increase in contraction time, relaxation time, and sustain

Table III. Summed left and right leg mean values and standard deviations for delay time, contraction time, relaxation time, sustain time, and maximal radial displacement or deformation of the biceps femoris before and after the ultra-endurance triathlon.

\begin{tabular}{lcc}
\hline & Before $(n=19)$ & After $(n=19)$ \\
\hline Contraction time & $65.1 \pm 22.1$ & $77.4 \pm 28.5^{a}$ \\
Deformation of muscle belly & $10.8 \pm 3.5$ & $13.4 \pm 4.6^{b}$ \\
Delay time & $44.1 \pm 5.4$ & $43.6 \pm 5.6$ \\
Sustain time & $436.8 \pm 68.1$ & $472.1 \pm 110.1$ \\
Relaxation time & $124.6 \pm 33.8$ & $151.8 \pm 35.9^{c}$ \\
\hline
\end{tabular}

$t$-test: ${ }^{a} P=0.008 ;{ }^{b} P=0.006 ;{ }^{c} P=0.011$. time) was observed, together with a moderate decrease in response time (delay time) and a loss of muscle stiffness (increase in maximal deformation of the muscle belly). Significant statistical differences were found between pre and post values of contraction time $(P=0.008)$, maximal radial displacement or deformation $(P=0.006)$, and relaxation time $(P=0.011)$. Non-significant differences were observed for delay time and sustain time. When the parameters are analysed individually (right leg only or left leg only), the results obtained differ. A significant difference $(P=0.006)$ was observed for maximal radial displacement or deformation of the biceps femoris only in the right leg, whereas significant differences were observed for contraction time $(P=0.038)$ and relaxation time $(P=0.012)$ in the left leg. A non-significant but suggestive trend was also found in maximal radial displacement or deformation $(P=0.077)$.

Summed left and right leg mean values and standard deviations for delay time, contraction time, relaxation time, sustain time, and maximal radial displacement or deformation of the rectus femoris before and after the ultra-endurance triathlon are presented in Table IV. Again, we observed an increase in the neural control of the muscle (increase in contraction time, delay time, relaxation time, and sustain time) and a decrease in stiffness (increase in maximal deformation of the muscle belly). For the rectus femoris, a significant difference between before and after the ultra-endurance triathlon was observed for delay time only $(P=0.003)$.

\section{Discussion}

The main findings of this study are that an ultraendurance triathlon race constitutes a physical effort that has a major impact on the functional capacities of the muscles involved. Several hours of swimming, cycling and running, with strenuous stretch-shortening cycle exercise, as occurs in an ultra-endurance triathlon, have considerable deleterious effects on neuromuscular function. These results are in line

Table IV. Summed left and right leg mean values and standard deviations for delay time, contraction time, relaxation time, sustain time, and maximal radial displacement or deformation of the rectus femoris before and after the ultra-endurance triathlon.

\begin{tabular}{lcc}
\hline & Before $(n=19)$ & After $(n=19)$ \\
\hline Contraction time & $63.5 \pm 13.1$ & $63.1 \pm 8.3$ \\
Deformation of muscle belly & $16.5 \pm 3.3$ & $16.7 \pm 5.5$ \\
Delay time & $45.6 \pm 4.1$ & $42.8 \pm 4.1^{a}$ \\
Sustain time & $233.7 \pm 76.8$ & $246.6 \pm 85.4$ \\
Relaxation time & $142.6 \pm 67.9$ & $157.8 \pm 73.9$ \\
\hline
\end{tabular}

t-test: ${ }^{a} P=0.003$. 
with those of other studies of fatigue in long endurance running events (Millet et al., 2000, 2002; Nicol et al., 1991; Viitasalo et al., 1982) and cycling (Crenshaw, Karlsson, Gerdle, \& Friden, 1997; Gerdle, Karlsoon, Crenshaw, \& Friden, 1997; Hakkinen \& Komi, 1983; St. Clair-Gibson, Schabort, \& Noakes, 2001.

In our opinion, radial muscle displacement, as well as the time values provided by tensiomyography, is very sensitive to muscle fatigue and to a certain extent also to the initial pressure of the sensor tip on the muscle. This same conclusion was drawn by Krizaj et al. (2008) in a study in which the short-term repeatability of tensiomyography was analysed.

The contraction times observed for the rectus femoris and biceps femoris in the present study were in excess of $30 \mathrm{~ms}$, which indicates muscles with a high prevalence of slow-twitch fibres (Dahmane et al., 2001) and therefore highly resistant to fatigue. Nevertheless, events lasting 9-12 h produce levels of fatigue in those muscles that have been put to work. However, muscular fatigue affects the two muscles studied in different ways. This is due to the varying degree to which the muscles examined participate at the very end of the ultra-endurance triathlon. In our study, a larger functional reduction was recorded in the posterior (biceps femoris) than the anterior (rectus femoris) musculature of the leg.

One should bear in mind that the role of the rectus femoris and biceps femoris varies, in form and intensity, during the stages of cycling and running. During the run, the last discipline of the ultraendurance triathlon race, the hamstring muscles (semitendinosus, semimembranosus, and biceps femoris) do not play a large role in the action of flexing the knee joint, since, over long distances, the raising of the heel during the recovery phase is a short and not very intense action. The main function of the hamstring muscles here is to provide traction on the ground during the support stage. During this stage, the hamstring muscles carry out a synergic action with the quadriceps muscles (rectus femoris, vastus lateralis, vastus medialis, and vastus intermedius). Extension and flexion of the knee joint leads to significant fatigue in the biceps femoris that affects the neural and morpho-functional mechanisms, which is reflected in the tensiomyography parameters: increase in contraction time, relaxation time, and sustain time but decrease in delay time and stiffness (increase in maximal deformation of the muscle belly). These results are in line with those of other authors (Bigland-Ritchie et al., 1986; Colliander et al., 1988; Edman \& Mattiazzi, 1981; Karatzaferi et al., 2008; Linssen et al., 1991; Metzger \& Moss, 1987; Thompson et al., 1992).

An interesting fact revealed by the data is the existence of a functional asymmetry between legs during physical activity (Figure 2). Tensiomyography shows us clearly that muscle work carried out by each leg during the ultra-endurance triathlon race is different, corresponding to technical errors by the athlete and the fact that this musculature is not in optimum condition. More intense activity is normally carried out by the dominant segment. In the long term, this would represent a high risk of injury for the athlete. We believe that in top-level athletes, with better pedal technique, these differences should be less evident.

We also assessed the rectus femoris in this study, an anterior muscle of the thigh that is unusual in that it is the only muscle in the quadriceps group that is involved in hip flexion, since it is the only muscle that originates in the pelvis and not the femur. This morphological characteristic leads the rectus femoris to fulfil support and impulse (take-off) roles during rear foot contact and those of synergist muscles in the flexing of the hip joint (lifting the thigh). During the support phase, the foot is in contact with the ground and supports the body against gravity. In the extension of the knee joint, the rectus femoris helps the free leg to move forwards by raising the thigh. The rectus femoris and other flexor muscles of the hip, together with the hamstring muscles, perform the recovery action during the pedalling motion. The behaviour of this muscle during the last two stages of the ultra-endurance triathlon led us to choose the rectus femoris rather than other quadriceps structures.

The effect of muscle fatigue on the rectus femoris was, in the present study, different from that found for the biceps femoris. Hardly any changes were observed in contraction time, relaxation time, sustain time, and maximal radial displacement or deformation of the muscle belly, while only the response time to contraction fell significantly (decrease in delay time; $P=0.003$ ). This could be due to the fact that the rectus femoris only has a relevant function during the cycling stage, and is less evident during the run. This obliges us to try to assess it on another occasion during the second transition (cycling-to-run) of the race.

In summary, the large loss in contractile capacity of the muscle following an ultra-endurance triathlon race is reflected in changes in the neuromuscular response and alterations in the contractile capacity of the muscle. These modifications, derived from a prolonged, exhausting effort, can be evaluated in a simple, non-aggressive way using tensiomyography.

In conclusion, this research provides additional evidence of the importance of being able to assess athletes during training and/or competition without the need for them to modify their normal work and rest routines. At the same time, the quality of 

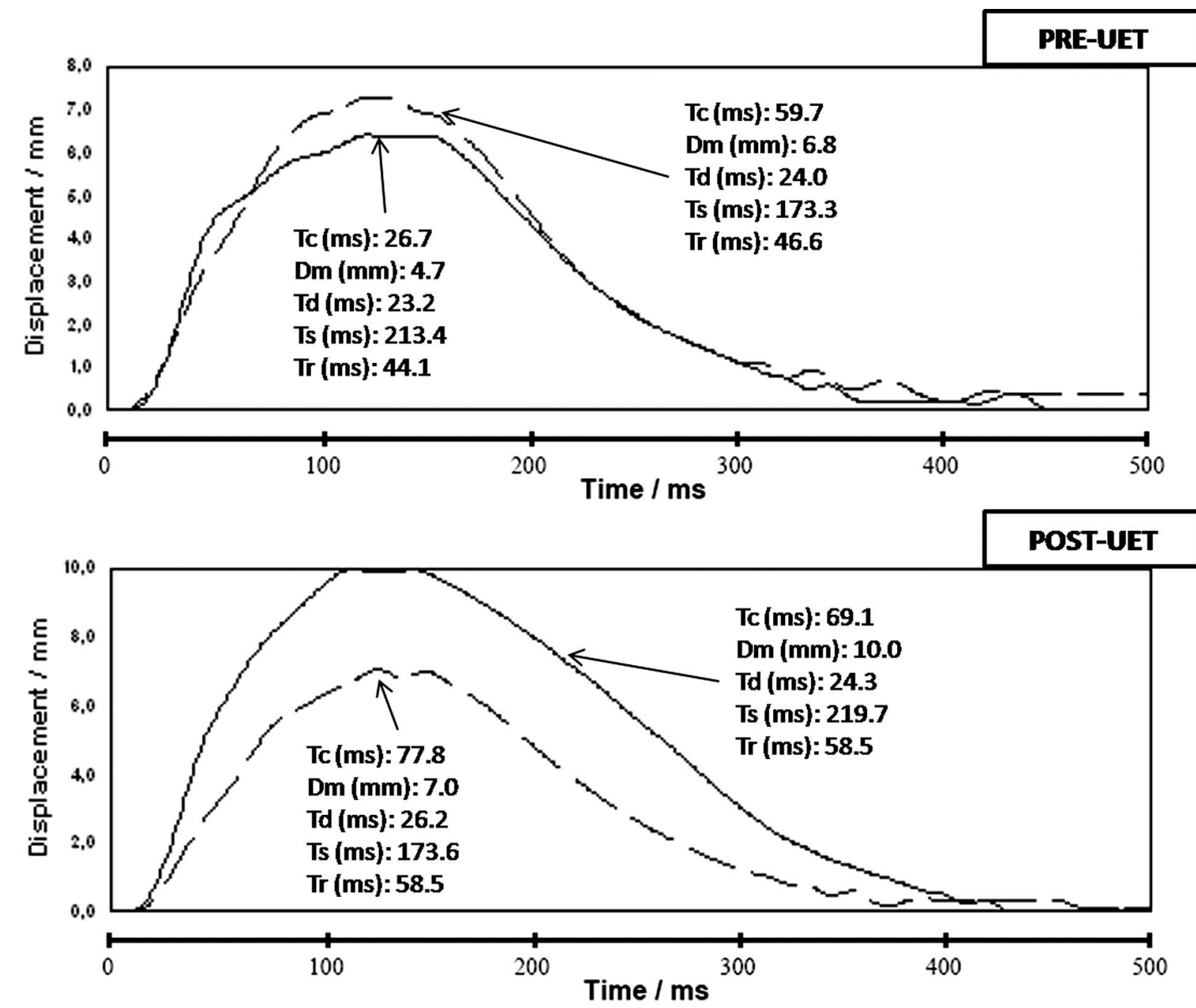

Figure 2. Muscle response to an electric stimulus obtained using tensiomyography on the biceps femoris of both legs ( left) before and after the ultra-endurance triathlon (UET) for a participant who completed the race in $12 \mathrm{~h}$ and 33 min. Maximal radial deformation or displacement of the muscle belly (Dm), contraction time (Tc), delay time (Td), sustain time (Ts), and relaxation time (Tr).

the assessment is ensured and yields important information as to the effects that the training process used has on the musculature.

\section{Acknowledgements}

The authors would like to thank Heather Adams and Gloria Perdomo Bautista, ULPGC, for translating this article into English.

\section{References}

Allen, D. G., Lamb, G. D., \& Westerblad, H. (2008). Skeletal muscle fatigue: Cellular mechanisms. Physiological Reviews, 88, 287-332.

Allen, D. G., \& Westerblad, H. (2001). Role of phosphate and calcium stores in muscle fatigue. Fournal of Physiology, 536, 657-665.

Bigland-Ritchie, B., Furbush, F., \& Woods, J. J. (1986). Fatigue of intermittent submaximal voluntary contractions: Central and peripheral factors. Fournal of Applied Physiology, 61, 421-429.
Clarkson, P. M., Nosaka, K., \& Braun, B. (1992). Muscle function after exercise-induced muscle damage and rapid adaptation. Medicine and Science in Sports and Exercise, 24, 512-520.

Colliander, E. B., Dudley, G. A., \& Tesch, P. A. (1988). Skeletal muscle fibre type composition and performance during repeated bouts of maximal, concentric contractions. European Fournal of Applied Physiology and Occupational Physiology, 58, 81-86.

Cooke, R., Franks, K., Luciani, G., \& Pate, E. (1988). The inhibition of rabbit skeletal muscle contraction by hydrogen ions and phosphate. Fournal of Physiology, 395, 77-97.

Coupland, M. E., Puchert, E., \& Ranatunga, K. W. (2001) Temperature dependence of active tension in mammalian (rabbit psoas) muscle fibres: Effect of inorganic phosphate. fournal of Physiology, 536, 879-891.

Crenshaw, A. G., Karlsson, S., Gerdle, B., \& Friden, J. (1997). Differential responses in intramuscular pressure and EMG fatigue indicators during low- vs. high-level isometric contractions to fatigue. Acta Physiologica Scandinavica, 160, 353-361.

Dahmane, R., Djordjevic, S., Simunic, B., \& Valencic, V. (2005). Spatial fiber type distribution in normal human muscle: Histochemical and tensiomyographical evaluation. Fournal of Biomechanics, 38, 2451-2459. 
Dahmane, R., Knez, N., Valencic, V., \& Erzen, I. (2000). Tensiomyography, a non-invasive method reflecting the percentage of slow muscle fiber in human skeletal muscles. In Book of Abstracts: Life Sciences 2000, Gozd Martuljek, Slovenia, 28 September - 1 October 2000.

Dahmane, R., Valencic, V., Knez, N., \& Erzen, I. (2001). Evaluation of the ability to make non-invasive estimation of muscle contractile properties on the basis of the muscle belly response. Medical and Biological Engineering and Computing, 39, $51-55$.

Davies, C. T. M., \& Thompson, M. W. (1986). Physiological responses to prolonged exercise in ultramarathon athletes. Fournal of Applied Physiology, 61, 611-617.

Debold, E. P., Dave, H., \& Fitts, R. H. (2004). Fiber type and temperature dependence of inorganic phosphate: Implications for fatigue. American fournal of Physiology: Cell Physiology, 287, C673-C681.

Edman, K. A. P., \& Mattiazzi, A. R. (1981). Effects of fatigue and altered $\mathrm{pH}$ on isometric force and velocity of shortening at zero load in frog muscle fibers. Fournal of Muscle Research and Cell Motility, 2, 321-334.

Fitts, R. H. (1994). Cellular mechanisms of muscle fatigue. Physiological Reviews, 74, 49-94.

Fitts, R. H. (2006). The muscular system: Fatigue processes. In C. Tipton (Ed.), ACSM's advanced exercise physiology (pp. 178196). Philadelphia, PA: Lippincott Williams \& Wilkins.

Gandevia, S. C. (2001). Spinal and supraspinal factors in human muscle fatigue. Physiological Reviews, 81, 1725-1789.

Gerdle, B., Karlsson, S., Crenshaw, A. G., \& Friden, J. (1997). The relationship between EMG and muscle morphology throughout sustained static knee extension at two submaximal force levels. Acta Physiologica Scandinavica, 160, 341-351.

Gibson, H., \& Edwards, R. H. (1985). Muscular exercise and fatigue. Sports Medicine, 2, 120-132.

Hakkinen, K., \& Komi, P. V. (1983). Electromyographic and mechanical characteristics of human muscle during fatigue under voluntary and reflex conditions. Electroencephalography and Clinical Neurophysiology, 55, 436-444.

Howell, J. N., Chleboun, G., \& Conatser, R. (1993). Muscle stiffness, strength loss, swelling and soreness following exerciseinduced injury in humans. Fournal of Physiology, 464, 183-196.

Karatzaferi, C., Franks-Skiba, K., \& Cooke, R. (2008). Inhibition of shortening velocity of skinned skeletal muscle fibers in conditions that mimic fatigue. American fournal of Physiology: Regulatory, Integrative and Comparative Physiology, 294, R948R955.

Krizaj, D., Simunic, B., \& Zagar, T. (2008). Short-term repeatability of parameters extracted from radial displacement of muscle belly. Fournal of Electromyography and Kinesiology, 18, 645-651.

Linssen, W. H. J. P., Stegeman, D. F., Joosten, E. M. G. H., Merks, J. H., Ter Laak, H. J., Binkhorst, R. A. et al. (1991). Fatigue in type I fibre predominance: A muscle force and surface EMG study on the relative role of type I and type II fibres. Muscle and Nerve, 14, 829-837.

Metzger, J. M., \& Moss, R. L. (1987). Greater hydrogen ioninduced depression of tension and velocity in skinned single fibres of rat fast than slow muscles. Fournal of Physiology, 393, $727-742$

Millet, G. Y., Lepers, R., Lattier, G., Martin, V., Babault, N., \& Maffiuletti, N. (2000). Influence of ultra-long term fatigue on oxygen cost of two types of locomotion. European fournal of Applied Physiology, 83, 376-380.
Millet, G. Y., Lepers, R., Maffiuletti, N. A., Babault, N., Martin, V., \& Lattier, G. (2002). Alteration of neuromuscular function after an ultra-marathon. Fournal of Applied Physiology, 92, 486492.

Newham, D. J., Jones, D. A., \& Clarkson, P. M. (1987). Repeated high-force eccentric exercise: Effects on muscle pain and damage. Fournal of Applied Physiology, 63, 1381-1386.

Nicol, C., Komi, P. V., \& Marconnet, P. (1991). Fatigue effects of marathon running on neuromuscular performance II: Changes in force, integrated electromyographic activity and endurance capacity. Scandinavian Fournal of Medicine and Science in Sports, $1,18-24$.

Nosek, T. M., Fender, K. Y., \& Godt, R. E. (1987). It is diprotonated inorganic phosphate that depresses force in skinned skeletal muscle fibers. Science, 236, 191-193.

Prasartwuth, O., Taylor, J. L., \& Gandevia, S. C. (2005). Maximal force, voluntary activation and muscle soreness after eccentric damage to human elbow flexor muscles. Fournal of Physiology, $567,337-348$.

Radin, E. L. (1986). Role of muscles in protecting athletes from injury. Acta Medica Scandinavica, 711 (suppl.), 143-147.

Rodríguez-Matoso, D., Quiroga, M. E., da Silva-Grigoletto, M., Bautista, P., Sarmiento, S., \& García-Manso, J. M. (2009). Evaluación de la reproducibilidad de la TMG. Congreso Internacional de Ciencias del deporte de la UCAM, 17-19 May 2009, Murcia.

Rusu, L., Cernaianu, S., Vasilescu, M., Baltac, G., Ciocanescu, D., \& Fortan, C. (2009). Assessment of knee stability using neuromuscular measurement in soccer players. In Proceedings of the XVIII International Congress on Sports Rehabilitation and Traumatology (pp. 98-99).

Sargeant, A. J., Hoinville, E., \& Young, A. (1981). Maximum leg force and power output during short-term dynamic exercise. Fournal of Applied Physiology, 51, 1175-1182.

Sayers, S. P., Peters, B. T., Knight, C. A., Urso, M. L., Parkington, J., \& Clarkson, P. M. (2003). Short-term immobilization after eccentric exercise. Part I: Contractile properties. Medicine and Science in Sports and Exercise, 35, 753-761.

St. Clair Gibson, A., Schabort, E. J., \& Noakes, T. D. (2001). Reduced neuromuscular activity and force generation during prolonged cycling. American fournal of Physiology: Regulatory, Integrative and Comparative Physiology, 281, R187-R196.

Thompson, L. V., Balog, E. M., Riley, D. A., \& Fitts, R. H. (1992). Muscle fatigue in frog semitendinosus: Alterations in contractile function. American fournal of Physiology: Cell Physiology, 262, C1500-C1506.

Valencic, V., Djordjevic, S., Knez, N., Dahmane, R., Coh, M., Jurcic-Zlobec, B. et al. (2000). Contractile properties of skeletal muscles detection by tensiomyographic measurement method. 2000 Pre-Olympic Congress, Brisbane, QLD, Australia, Abstract 507.

Valencic, V., \& Knez, N. (1997). Measuring of skeletal muscles dynamic properties. Artificial Organs, 21, 240-242.

Valencic, V., Knez, N., \& Simunic, B. (2001). Tensiomyography: Detection of skeletal muscle response by means of radial muscle belly displacement. Biomedical Engineering, 1, 1-10.

Viitasalo, J. T., Komi, P. V., Jacobs, I., \& Karlsson, J. (1982). Effects of prolonged cross-country skiing on neuromuscular performance. Exercise and Sport Biology, 12, 191-198.

Westerblad, H., Allen, D. G., Bruton, J. D., Andrade, F. H., \& Lännergren, J. (1998). Mechanisms underlying the reduction of isometric force in skeletal muscle fatigue. Acta Physiologica Scandinavica, 162, 253-260. 